\title{
Novas Perspectivas nos Estudos sobre MoVimentos SOCIAIS NO ISLÃ E NO MUNDO MUÇULMANO
}

Resenha do Livro: Social Movements, Mobilization and Contestation in the Middle East and North Africa (Joel Beinin e Frédéric Vairel

Organizadores), Ed. Stanford, CA, 2011

por Ariel Finguerut ${ }^{1}$

Fruto de um seminário entre 2008 e 2009, promovido pelo Centro de Estudos sobre Oriente Médio da American University no Cairo, Egito, e com apoio da Fundação Ford, o livro editado pelo professor de Stanford, Joel Beinin e por Frédéric Vairel, da Universidade de Ottawa, reúne textos de 11 pesquisadores de diferentes nacionalidades com distintas perspectivas, mas todos de certa forma, unidos por uma discussão focada nas formas de mobilização de grupos, movimentos e atividades políticas e sociais no Oriente Médio e Mundo Muçulmano num recorte contemporâneo.

É sempre um grande desafio buscar marcas comuns ou uma grande teoria para explicar um contexto tão diverso e plural com nuanças históricas e particularidades identitárias? e políticas como é o Oriente Médio e o próprio islã e o mundo muçulmano. Por outro lado, é possível identificar algumas marcas em comum, como os regimes autocráticos, a alta corrupção, os abusos sistemáticos do poder do Estado, a concentração de renda, baixo desenvolvimento humano e, diante destas marcas, surge uma questão interessante que os textos - em seu conjunto parecem querer responder: como os árabes e os muçulmanos de forma mais ampla se mobilizam e reagem a estas marcas a este quadro de repressão e de

\footnotetext{
${ }^{1}$ Doutorando do programa de Ciência Política da Universidade Estadual de Campinas (Unicamp), bolsista da Fundação de Amparo à Pesquisa do Estado de São Paulo ( Fapesp), pesquisador do Grupo de Trabalho Oriente Médio Mundo Muçulmano ( GT OMMM) , membro do conselho editorial do Boletim Malala. Contato: arielfing@gmail.com
} 
marginalidade diante da riqueza e do desenvolvimento de suas elites, seus governos e do resto do mundo?

Tentando responder a esta pergunta o livro traz grande contribuição ao debate sobre o islã, o mundo muçulmano e para todos os interessados nas relações internacionais e na política internacional contemporânea. Pois, justamente se perguntando como estudar movimentos sociais e políticos no islã e como ocorrem as mobilizações e reações políticas percebemos - capitulo a capitulo - como estereótipos vão sendo desconstruídos e, apesar do livro ser anterior à chamada Primavera Árabe, movimento que derrubou regimes e mobilizou milhares de pessoas pelo Mundo Muçulmano, o livro contribui para entendermos por outras perspectivas esta grande mobilização. A principal questão é desmistificar a ideia de que, no Oriente Médio e no islã como um todo, não haveria movimentos sociais ou seus movimentos teriam um lógica distinta da Ocidental ou dos movimentos encontrados em outros lugares. O livro deixa claro que a luta dos movimentos sociais que existem na Tunísia, no Marrocos, Egito, Arábia Saudita, Turquia e por todo mundo muçulmano, alguns voltados para direitos civis, outros a causas GLBT ou ainda o ativismo estudantil e movimentos de mulheres e de direitos humanos não é distinto e não difere em nada das lutas e movimentos sociais que encontramos em outras regiões do mundo.

Esta constatação é central para superar estigmas como a de que o islã seria essencialmente antiocidental ou que fundamentalmente ideias como democracia e diretos humanos não teriam sustentação ou respaldo social entre muçulmanos. $\mathrm{Na}$ medida em que pesquisadores se voltam para movimentos sociais no mundo muçulmano se deparam com atores que lutam por direitos (sociais, trabalhistas ou humanos) e que criam estratégias para enfrentar e se mobilizar politicamente num contexto marcado por grande repressão, que ocorre as vezes, de forma discriminada outras vezes seletiva e preemptiva. O fato de lidar com uma mobilização marcada pela repressão não faz destes movimentos algo estranho aos estudos dos movimentos sociais a cargo da sociologia política ou dos cientistas políticos e historiadores feitas no Ocidente ou em outros lugares do mundo. A peculiaridade destes movimentos pode estar em pensar como árabes e muçulmanos desafiam os governos e seus aparatos repressivos. Em outras palavras, como árabes e muçulmanos desobedecem e desafiam a autoridade? 
Neste sentido, a discussão dos autores deste livro avança para questões que são muito importantes não só para a pesquisa sobre o mundo muçulmano mas também para o próprio debate teórico sobre movimentos sociais, na medida em que se desdobram em questões e grandes dilemas do debate contemporâneo como a relação entre o islã e os valores, práticas e os caminhos e descaminhos para a democracia, entre formas de resistência, iniciativas reformistas ou processos revolucionários e contrarrevolucionários. Esta discussão nos faz atentos para o fato de que a mobilização social no islã não é , como em qualquer outro lugar, unidirecional, isso quer dizer que, assim como há movimentos lutando por direitos humanos, por melhores condições de trabalho e por mais democracia, há movimentos como os discutidos no livro, no caso do Jama'a al-Islamiyya do Egito e do Hizbullah no Líbano que se mobilizam, se organizam visando espaços de resistência para um islã anti-Ocidente e que buscam práticas visando uma determinada visão do que é ser muçulmano e como ser um melhor muçulmano. Vale notarmos que, muitas vezes, estes movimentos usam instrumentos ocidentais, com programas de TV no caso do Hizbullah ou já utilizaram símbolos do turismo ocidental com as pirâmides no Egito no caso do Jama‘a al-Islamiyya para apresentarem sua agenda, suas reinvindicações e como instrumento de mobilização.

Entre as muitas colaborações do livro, destacamos brevemente, Pascal Menoret que estuda o caso do Arábia Saudita mostrando como neste país há duas caraterísticas marcantes nos movimentos socias, a grande e violenta repressão por parte do governo que torna o engajamento uma escolha de alto risco e o contexto saudita de revival religioso que fomenta um islã salafista que, muitas vezes, também desafia a ordem mas visando uma aderência ainda mais direta e estrita ao islã. Já Frédéric Vairel compara Egito e Marrocos num contexto de protestos em regimes autoritários mostrando que em ambos os casos as mobilizações são antigas, datam da década de 90, falando em "onda democrática" num contexto em que ambos países são fortemente influenciados pelo que acontece no mundo. Neste sentido Vairel desmistifica a ideia de "despertar" repentino dos marroquinos e egípcios mostrando que protestos contra o governo e grandes manifestações envolvendo não só questões locais mas também protestos contra Israel ou contra os Estados Unidos ocorrem com grande intensidade há pelo menos vinte anos. Ainda sobre o Egito, 
Marie Duboc nos ajuda a entender como intelectuais de esquerda são historicamente importantes na política egípcia e de como estes intelectuais desempenham historicamente um papel de ligação entre as ideias de esquerda e o debate político sendo muitos deles, seculares e vistos socialmente uma espécie de "guardiões da nação".

Sobre direito humanos, Joe Stork faz um amplo panorama discutindo o tema em países como Bahrain, Egito, Marrocos e Turquia mostrando que nenhum governo - seja Ocidental ou não - gosta de ser cobrado por direitos humanos. A diferença no caso destes países analisados e que muitas vezes por serem vítimas de intensa e violenta repressão, movimentos sociais islamitas não abraçam uma luta por direitos humanos mas aceitam e dialogam com movimentos que estão lutando pelo direito de se manifestaram por direitos humanos. Neste sentido, Stork mostra relações que são aparentemente contraditórias entre a luta por direitos humanos com movimentos radicais, seja de esquerda como no caso do Marrocos, seja islamita, como no caso do Bahrein ou como consequência de um crescente número de presos políticos, como no caso da Turquia dos anos de 1980. Ainda sobre a Turquia, Zeynep G. Göker mostra como uma manifestação pacífica, a prática de uma vigília em praça pública, a Saturday Mothers, conseguiu chamar atenção para o problema dos prisioneiros políticos na Turquia e_transformou-se rapidamente numa experiência de desobediência civil atraindo não só a mídia internacional mas outros movimentos de prisioneiros políticos como as Madres de Plaza de Mayo, movimento argentino de mobilização em torno dos desaparecidos políticos durante a ditadura militar argentina, que estiveram e protestaram em solidariedade com as Saturday Mothers .

Em torno da mobilização dos trabalhadores e o tema do trabalho, Montserrat E. Badimon, nos mostra que no caso do Marrocos uma intensa correlação entre a falta de emprego para jovens formandos e a mobilização por emprego ocorre desde dos anos 90 ameaçando e questionando a legitimidade do governo. Neste sentido, não ter emprego ou não ter oportunidade de conseguir um emprego, desperta na sociedade o forte sentimento de injustiça de modo que, mesmo quando o governo por meio de torturas e repressões violentas tenta impedir as mobilizações, elas se espalham, alimentadas pelo senso de injustiça. Neste processo, Badimon nos ajuda 
a entender por que, diante da Primavera Árabe especialmente no Marrocos na Tunísia e no Egito, foram os jovens desempregados os principais protagonistas.

Por fim, restou aos editores Joel Beinin e Frédéric Vairel fazerem um "pósescrito" relacionando a discussão do livro aos primeiros sinais de transformação da Primavera Árabe. Os autores se concentram no caso da Tunísia e do Egito mostrando haver em comum o fato dos protestos serem majoritariamente organizados por jovens que há décadas enfrentam de geração para geração enfrentam os mesmos problemas econômicos estruturais como alto desemprego, alta inflação e resquícios como ressentimentos da agenda liberal que assim como em outras regiões do mundo foi amplamente adotada nos anos 90 no norte da África. Os editores também enfatizam que foram protestos em que a mídia "chegou depois" e que enfrentavam também resquícios e ressentimentos de um regime autoritário que historicamente tratava com brutalidade qualquer protesto e que convivia com milícias e práticas corruptas. No caso da Tunísia, o governo desde 2008 já demostrava grande dificuldade para controlar protestos e manifestações que muitas vezes além dos jovens e desempregados envolviam também setores tradicionais da sociedade e da economia tunisiana, como professores e mineiros, dois setores que são historicamente bem organizados e mobilizados.

Em síntese, o livro Social Movements, Mobilization and Contestation in the Middle East and North Africa, compila discussões e traz perspectivas que são fundamentais e extremamente relevantes para quem se interessa e busca entender de forma mais ampla tanto as raízes da Primavera Árabe como a própria dinâmica das mobilizações e dos movimentos sociais do Mundo Muçulmano. 